\title{
ASO Video Abstract: Effect of Phased Implementation of Totally Minimally Invasive Ivor Lewis Esophagectomy for Esophageal Cancer after Previous Adoption of the Hybrid Minimally Invasive Technique: Results from a French Nationwide Population-Based Cohort Study
}

\author{
Frederiek Nuytens, $\mathrm{MD}^{1,2}$ (1) , Xavier Lenne, $\mathrm{MSc}^{3}$, Guillaume Clément, $\mathrm{MD}^{3}$, Amelie Bruandet, $\mathrm{MD}, \mathrm{PhD}^{3}$, \\ Clarisse Eveno, $\mathrm{MD}, \mathrm{PhD}^{1,4}$, and Guillaume Piessen, $\mathrm{MD}, \mathbf{P h D}^{1,4}$ \\ ${ }^{1}$ Department of Digestive and Oncological Surgery, Claude Huriez University Hospital, University Lille, Lille, France; \\ ${ }^{2}$ Department of Digestive and Hepatobiliary/Pancreatic Surgery, AZ Groeninge Hospital, Kortrijk, Belgium; ${ }^{3}$ Medical \\ Information Department, Lille University Hospital, Lille, France; ${ }^{4}$ CNRS, Inserm, CHU Lille, UMR9020-U1277 - \\ CANTHER - Cancer Heterogeneity, Plasticity and Resistance to Therapies, University Lille, Lille, France
}

We evaluated nationwide the short-term outcomes of totally minimally invasive esophagectomy after previous adoption of the hybrid minimally invasive technique. Totally minimally invasive esophagectomy is associated with a reduced 90-day postoperative mortality compared with open esophagectomy and offers reduced rates of pulmonary complications compared with open esophagectomy and hybrid minimally invasive techniques (https://d oi.org/10.1245/s10434-021-11110-x).
Supplementary Information The online version contains supplementary material available at https://doi.org/10.1245/s10434021-11144-1.

Publisher's Note Springer Nature remains neutral with regard to jurisdictional claims in published maps and institutional affiliations.

(C) Society of Surgical Oncology 2021

Published Online: 12 January 2022

F. Nuytens, MD

e-mail: frederiek.nuytens@gmail.com 